ENCYCLOPEDDIE Encyclopédie berbère

BERBERE

$23 \mid 2000$

23 | Hiempsal - Icosium

\title{
Ibn Khaldoun
}

G. Camps

\section{OpenEdition}

Journals

Édition électronique

URL : http://journals.openedition.org/encyclopedieberbere/1628

DOI : 10.4000/encyclopedieberbere.1628

ISSN : 2262-7197

\section{Éditeur}

Peeters Publishers

\section{Édition imprimée}

Date de publication : 1 octobre 2000

Pagination : $3600-3604$

ISBN : 2-7449-0207-1

ISSN : 1015-7344

\section{Référence électronique}

G. Camps, «Ibn Khaldoun », Encyclopédie berbère [En ligne], 23 | 2000, document I10, mis en ligne le 01 juin 2011, consulté le 25 septembre 2020. URL : http://journals.openedition.org/encyclopedieberbere/ 1628 ; DOI : https://doi.org/10.4000/encyclopedieberbere.1628

Ce document a été généré automatiquement le 25 septembre 2020

(c) Tous droits réservés 


\section{Ibn Khaldoun}

\section{G. Camps}

1 Alors que la Reconquista se poursuit en Andalus et menace l'Occident musulman, à l'autre extrémité de l'empire arabe se répand la menace mongole annonciatrice de pillages et de massacres. Les États arabes et arabo-berbères du Maghreb et de l'Espagne musulmane connaissent déchirements et assassinats, dus aux confrontations fratricides. Au Maghreb dont les royaumes à géométrie variable se définissent par leurs capitales: Fès des Mérinides, Tlemcen des Abdelwadid, Tunis des Hafcides, d'autres cités sont appelées à jouer le rôle de capitales de principautés plus ou moins dépendantes des trois grands sultanats. C'est le cas de Bejaia (Bougie) et de Constantine, qui exercent leur suzeraineté sur des territoires que ces vieilles cités se disputent sans cesse. Trahisons, rapines, attentats sont la réalité quotidienne de ces États immatures. C'est en cette période de déchirements que naquit à Tunis Wali ed Din Abd er-Rahman ben Mou-hammad ibn Khaldoun. La famille d'Ibn Khaldoun était arabe, originaire d'Al Andalus comme des centaines d'autres qui apportèrent à la Tunisie leur savoir, leur technicité et leur maîtrise dans le domaine agricole. Sa famille s'était fixée à Séville depuis plusieurs générations et ses ancêtres avaient exercé de hautes fonctions civiles. Le jeune Ibn Khaldoun reçut une éducation soignée qui le prépara à devenir un maître réputé en de nombreux domaines. Il acquit une connaissance parfaite du Coran, du Hadith et du Fik. Grâce à l'arrivée massive à Tunis de nombreux savants dans la suite du Mérinide Abd el-Hassan, momentanément maître de Tunis, le jeune Ibn Khaldoun profita pleinement de la Science qui lui était ainsi révélée et garda un souvenir reconnaissant à ses maîtres, dont il peint les mérites dans son Tarif (autobiographie). Mais aux temps heureux succèdent les jours de deuil. En 1340, la peste noire faisait son entrée à Tunis dont, en quelques semaines, elle décima la population. Les parents d'Ibn Khaldoun étaient au nombre des victimes ; il avait 17 ans.

2 C'est en 1350 (753 Hégire) que commence sa carrière politique; il passe au service du Mérinide Abu Ishaq; mais la défaite subie par le sultan de Fès lui fait commettre sa première volte-face qui sera suivie de nombreuses autres. Il fausse compagnie aux Mérinides (1352) et entreprend un premier voyage coupé de plusieurs séjours dans les marges de l'Ifriqiya, à Ebba, puis Tébessa, ensuite Gafsa et, en dernier lieu, Biskra où il passe l'hiver chez les Beni Muzni, amis de sa famille. C'est de Biskra qu'Ibn Khaldoun, 
changeant d'attitude, fait acte d'allégeance auprès du nouveau maître de Fès, Abu Hinan (successeur d'Abu Hassan) qui s'est emparé de Tlemcen et répond favorablement aux offres de services d'Ibn Khaldoun. En attendant de rejoindre Fès, le jeune érudit s'arrête pour quelques mois à Bougie (1352-1353).

Les voyages d'Ibn Khaldoun (d'après G. Camps).

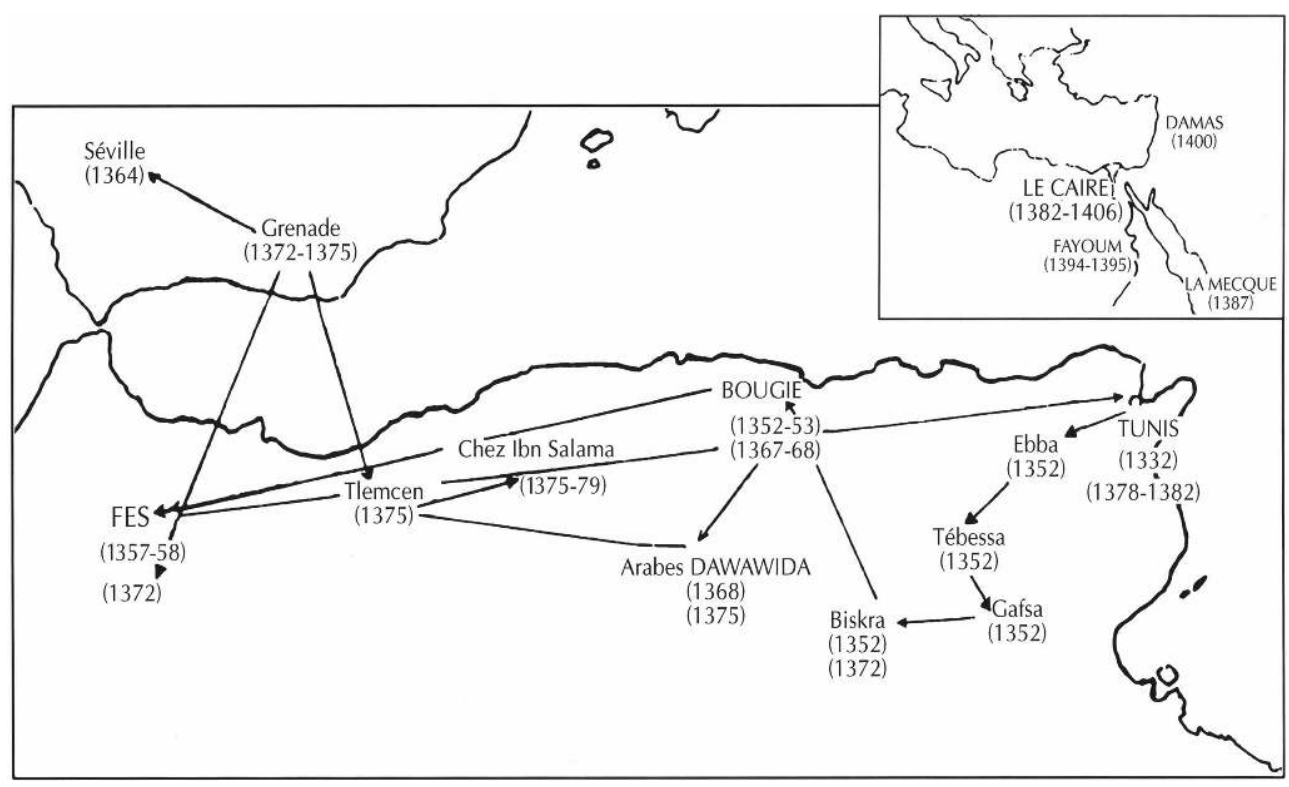

Dès son arrivée à Fès, Ibn Khaldoun est accueilli dans le secrétariat du sultan, mais son ambition s'accorde mal avec cette fonction qu'il juge indigne de son rang. Les circonstances et, particulièrement la maladie d'Abu Hinan, semblent l'avoir incité à conspirer contre ce sultan, dans l'intention de rétablir Abu Abd Allah à Bougie; mais, bien qu'il attribue son échec à la malveillance et à la jalousie des courtisans, il est dénoncé et jeté en prison. Son internement dura deux ans et prit fin à la mort d'Abu Hinan (1358). Une fois libéré, il obtient du nouveau sultan le poste de secrétaire de la chancellerie. Mais les intrigues reprennent: Ibn Khaldoun craint maintenant pour sa vie et, non sans difficultés, il obtient en 1362 l'autorisation de se rendre à Grenade où le roi naçride Abu Mohammad ben al Ahmar a retrouvé son trône et son grand vizir Ibn al Khattib qui, lorsqu'il s'était réfugié à Fès, avait été conquis par la science et l'intelligence d'Ibn Khaldoun. Celui-ci reçut un excellent accueil à Grenade et fut chargé de négocier un traité de paix avec Pierre II le Cruel, roi de Castille (1364). De nouvelles intrigues de cour et la jalousie d'Ibn el Khattib incitent Ibn Khaldoun à quitter Grenade (1365).

4 A Bougie, les circonstances se présentent favorablement pour lui depuis que Mohammad ben el Ahmar a recouvré son trône. Le souverain nomme Ibn Khaldoun chambellan (Hidjaba*), tandis que son frère cadet, Yahya Ibn Khaldoun devient vizir. Entre-temps, la réputation d'Ibn Khaldoun se répand largement à travers le Maghreb, ce qui justifie les fonctions supplémentaires de professeur de Fiq et de prédicateur qu'il exerce à Bougie. Mais il renonce bientôt à ces honneurs, car, une fois de plus, il est en butte aux attaques de la cour et de l'envie des puissants, du moins le prétend-il, et, vraisemblablement, ses propres intrigues l'incitent à abandonner la carrière politique pour se consacrer entièrement à la science et à la recherche. Il aspirait à la paix mais il devait être maintes fois sollicité ou attiré dans de nouvelles intrigues. 
5 Après un séjour de réflexion dans le Ribât d'Abu Madyan, il retourne à Fès (1372) où il espère échapper aux sollicitations politiques et pouvoir se consacrer définitivement à l'étude. Mais, de son passé lui reste accolée l'image d'un intrigant, d'un conjurateur, bref, d'un homme dangereux.

De retour au Maghreb, il fait venir sa famille à Tlemcen (1375) et, pendant quatre ans, il demeure au château d'Ibn Salama à Tagurzout, près de Frenda. C'est dans cette retraite paisible qu'il rédigea la Mukaddima. Cette "introduction" au Kitab al 'Ibar (Histoire universelle) est son œuvre maîtresse. Cet ouvrage d'un historien génial et parfaitement lucide compte six parties après l'introduction où l'Histoire est définie comme une Science, les bases de la méthodologie de l'historiographie sont exposées.

7 1. Sociologie générale de la civilisation: théorie de la sociabilité naturelle; déterminations $\mathrm{du}$ milieu et leur incidence culturelle; géographie physique et humaine ; ethnologie et arts divinatoires.

2. Sociologie de la bédouinité : étude de deux types de groupements humains; de l'état de nomade à celui de citadin ; concept de 'assabiyya (cohésion sociale).

3. Philosophie politique: origine et exercice du pouvoir et de l'autorité spirituelle, théorie des institutions.

4. Sociologie de la citadinité (hadara) : phénomènes urbains ; organisation et économie de la cité ; typologie du citadin.

5. Économie politique : industrie ; travail ; classes sociales.

6. Sociologie de la connaissance: classification des Sciences; langage et société, pédagogie ; disciplines philosophiques et littéraires.

Donnant à sa recherche historique une dimension qui élève l'Histoire au rang d'une Science, Ibn Khaldoun nous paraît étonnamment moderne dans le rationalisme de sa démarche qui exclut l'appel au fait religieux. Pour rédiger les Prolégomènes (Mukkadima), Ibn Khaldoun doit pouvoir disposer d'une documentation considérable ; celle qu'il a constituée au château d'Ibn Salama est entièrement exploitée. Il lui faut reprendre son bâton de pèlerin et commencer l'exploitation des archives des Hafçides de Tunis.

9 Sortant de sa studieuse demeure où il vient de passer quatre ans de réflexion et de rédaction, Ibn Khaldoun décide de retourner dans sa ville natale où il revient âgé de 37 ans, après une absence de vingt années. Désormais, il semble se résigner: c'est à l'enseignement qu'il se consacre pleinement. Et, caché dans sa tour d'ivoire, il poursuit son œuvre, achève une première édition du Kitab al 'Ibar. Son autobiographie (Tar'if) connaît aussi un succès mérité mais, une fois de plus, les faveurs dont jouit Ibn Khaldoun de la part du souverain provoquent jalousies et haines. La cabale qui se constitue autour du vizir Ibn Arafa incite Ibn Khaldoun à quitter définitivement le Maghreb. Le sultan de Tunis lui ayant permis de se rendre en pèlerinage, en octobre 1382, il s'embarque à destination d'Alexandrie. Sa renommée le précède au Caire où il s'établit à demeure et obtient d'occuper la chaire de droit malikite à la medrasa $\mathrm{Al}$ Commhiyya ainsi qu'à Alazzar. Sa nomination comme grand kadi malikite (1384) couronne sa carrière. Après quatorze années consacrées à l'enseignement, il est une nouvelle fois nommé kadi et doit suivre - sans enthousiasme - le maître du moment, Al Nasir. Celui-ci ne parvint pas à arrêter Tamerlan qui s'était emparé d'Alep et du nord de la Syrie ; alors que le mameluk retourne précipitamment en Égypte, Ibn Khaldoun resté à Damas entre en rapport avec Tamerlan pour qui il rédige une description du Maghrib. Mais les bonnes relations établies entre ces deux hommes n'empêchent pas le pillage et 
l'incendie de Damas (1400). Il ne semble pas que sa réputation ait eu à souffrir de l'intérêt que lui porta Tamerlan. Rentré au Caire, il poursuit la rédaction de ses écrits, en particulier le Kitab al 'Ibar dont il envoie une copie au sultan mérinide Abu Faris.

A la fin de sa vie, il s'intéresse au mysticisme soufi mais il n'est pas sûr qu'il ait été l'auteur du traité Shitac al Sa'il

Il meurt au Caire le 26 ramadan 808 (Hégire) - le 17 mars 1406.

12 Aux yeux des historiens contemporains, Ibn Khaldoun est considéré comme le fondateur génial de l'histoire scientifique telle que la conçoivent aujourd'hui certaines écoles, telles que l'école des Annales, l'histoire des mentalités et autres. Plus simplement, nous dirons qu'Ibn Khaldoun a introduit la sociologie et la plupart des sciences humaines dans la trame historique.

\section{BIBLIOGRAPHIE}

ARNALDEZ R., "Réflexion sur un passage de la Mukaddima d'Ibn Khaldun”, Mélanges R. Crozet, Poitiers, 1966, p. 1377 sq.

ATALlaH BoRham M., La pensée économique d'Ibn Khaldun, Thèse d'Université, Paris, 1964.

BEN CHEIKH E., "Ibn Haldun”, Encyclopcedia Universalis, t. 8, p. 700.

BIELZAWSKI J., “Aspect sociologique des opinions d'Ibn Haldun sur les sciences de la langue arabe”, Atti del Terzo Congr., di Studi arabi e islamici, Naples, 1967.

BOUTHOUL G., Ibn Khaldoun, sa philosophie sociale, Paris, 1930.

BOUSQUET G.-H., Les textes sociologiques et économiques de la Mukaddima, Paris, 1965.

BRUNSCHVIG R., La Berbérie orientale sous les Hafsides, Paris, 1947, t. II, p. 385-393.

HUSSEIN T., Étude analytique et critique de la philosophie sociale d'Ibn Kahldûn, Paris, 1917.

LABICA G., “Esquisse d'une sociologie de la religion chez Ibn Khaldûn”, La Pensée, octobre 1965.

LACOSTE Y, Ibn Khaldoun, naissance de l'histoire, passé du Tiers Monde, Paris, 1966.

MAHDI M., Ibn Khaldûn's philosophy of history, Londres, 1957.

NASSAR N, “Le maître d'Ibn Khaldûn : al Abili”, S. I. XX, 1964, p. 103-115.

NASSAR N, La pensée réaliste d'Ibn Khaldûn, Paris, 1967.

PERES H., “Bibliographie sur la vie et l'œuvre d'Ibn Haldûn”, Mélanges Levi Della Vida, II, p. 308-329.

TALBI M., “Ibn Haldûn et le sens de l'histoire”, S. I., XXVI, 1967, p. 73-148.

TALBI M., “Ibn Khaldûn”, Encyclopédie de l'Islam, nouvelle édition, p. 849-855. 
INDEX

Mots-clés : Moyen Âge, Personnage 